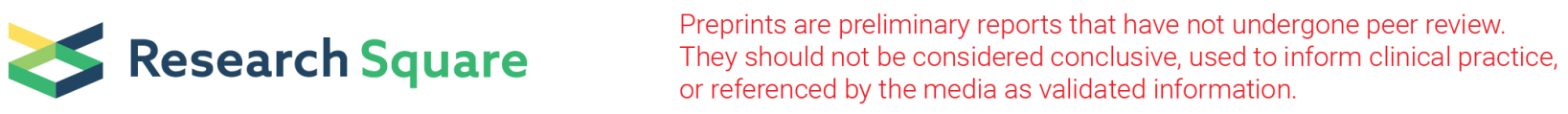

\title{
B blood group is related to decreased risk of incidence and severity of coronary artery disease in elderly adults with hypertension
}

Yanbin Song ( $\sim$ songyb1984@126.com )

Wujin Hospital Affiliated with Jiangsu University

Gaojun Cai

Wujin Hospital Affiliated with Jiangsu University

\section{Research Article}

Keywords: B blood group, coronary artery disease, elderly, hypertension, Gensini score, severity

Posted Date: February 17th, 2022

DOI: https://doi.org/10.21203/rs.3.rs-1354603/v1

License: (c) (i) This work is licensed under a Creative Commons Attribution 4.0 International License.

Read Full License 


\section{Abstract}

Background Although ABO blood groups have been associated with cardiovascular disease, little is known about whether $\mathrm{ABO}$ blood groups contribute to the risk of incidence and severity of coronary artery disease (CAD) in elderly adult with hypertension. Here, the study was carried out to explore the association.

Methods 793 hypertensive patients aged 60 years or older of 2095 cases who consecutively underwent primary coronary angiography were retrospectively included. They were divided into CAD and non-CAD groups. Demographic and clinical characteristics, $A B O$ blood groups and other biochemical parameters of both groups were collected and compared. Further evaluation was performed to determine the impact of $A B O$ blood groups on $C A D$ severity using Gensini score and the number of significantly diseased vessels. Logistic regression model was constructed to identify the association of ABO blood groups with CAD.

Results There was substantial difference in distribution of ABO blood groups in elderly and hypertensive adults with and without CAD $(p=0.022)$. Hypertensive patients with CAD had significantly lower distribution of $B$ blood group than those without CAD $(p=0.008)$. Compared to those with non-B blood groups, hypertensive elderly with B blood group tended to have significantly lower concentrations of TC, LDL-C and Apo B, and statistically lower number of significantly stenosed vessels. B blood group was found to be an independently protective factor for CAD in elderly with hypertension.

Conclusions B blood group was significantly associated with a decreased risk of CAD and was correlated with severity of coronary stenosis in elderly with hypertension.

\section{Introduction}

Coronary artery disease (CAD) is a well-documented major threat to human health worldwide nowadays, and accounts for approximately 17.8 million deaths annually. It is the leading cause of mortality and disability, and it is also preventable $[1,2,3,4]$. There is robust evidence that environmental and genetic factors contribute to the risk of CAD [5,6]. And it is well-known that hypertension is a significant risk of CAD in different populations.

ABO blood group, as a genetic risk factor, has been demonstrated to be related with cardiovascular disease and cardiac deaths in overall population. Although the relationship is still controversial, multiple studies have reported that people with A blood group are more vulnerable to coronary stenosis compared with those with non-A blood groups, and individuals with $O$ blood group have been linked with lower risk of CAD $[7,8]$. Moreover, a study performed in Bangladeshi people revealed that $\mathrm{O}$ blood group was associated with a substantially increased risk for CAD [9]. In addition, AB blood group has been reported to play an important role in a decreased risk of CAD [10]. Thus, the association of $A B O$ blood groups with the development of CAD is inconsistent in different races and populations. 
The above reports have been carried out in general population, few reports focus on the association between $A B O$ blood group and CAD in elderly with hypertension. On the other hand, a possible protective effect of B blood group on several diseases including cardiovascular events was observed. It is reported that patients with $\mathrm{B}$ blood group are less likely to develop pancreatic neuroendocrine tumors and other types of pancreatic masses in Chinese population [11]. Meanwhile, a nationwide cohort study suggested that $B$ blood group conferred a lower risk of aortic aneurysms when compared with $O$ blood group [12]. Individuals with $B$ blood group account for approximately $25 \%$ of Chinese population. It is necessary to pay more attention to the relationship between $C A D$ and $B$ blood group for its big sample size. To the best of our knowledge, whether $B$ blood group contributes to CAD risk and severity of CAD has not been clearly established.

Of note, age itself is a well-established risk factor for the development of cardiovascular disease, and elderly people are associated with increased CAD because of age-mediated damage [13]. As we all know, several conventional risk factors including smoking, male gender, hyperlipidemia and prior history of hypertension for incident CAD are different between older and young patients [14,15,16]. A study conducted in Chinese Taiwan young adults indicated that A blood group was an independent risk factor for $C A D$ and myocardial infarction as compared to non-A blood groups [17]. Whereas evidence is not fully available regarding the relationship between distribution of $A B O$ blood groups and CAD risk as well as severity assessed by the Gensini score and the significantly diseased vessels in subjects aged 60 years or older, especially in those with hypertension.

Therefore, we conducted this study to elucidate the relationship between ABO blood groups and CAD by retrospective analysis on the data of elderly adults with hypertension undergoing primary diagnostic coronary angiography (CAG) at our center.

\section{Methods}

\section{Study participants}

A total of 793 elderly cases with hypertension (mean age of $69.13 \pm 5.81$ years, $62.6 \%$ was males) from 2095 subjects who hospitalized due to symptoms of angina, coronary myocardial infarction or heart failure, were consecutively included. All the study patients underwent primary CAG at the Department of Cardiology, the Wujin Hospital Affiliated with Jiangsu University between 2014 and 2018.

Ineligible patients were excluded if they: (1) had severe hepatic or renal dysfunction $(n=2)$, hyperthyroidism or hypothyroidism ( $n=29)$; (2) had previous lipid-lowering therapy in 3 months prior to our study ( $n=136)$; (3) lacked information about ABO blood groups or lipid profiles $(n=381)$; (4) was younger than 60 years $(n=480)$; $(5)$ without hypertension.

Two experienced cardiologists evaluated the CAG results. CAD was defined as stenosis of $50 \%$ or more of the diameter of the major coronary vessels. Patients were divided into CAD and non-CAD groups based on the CAG results. 
The written informed consents were not presented from the included patients because the relevant data were retrospectively obtained from the electronic medical records. Our study complied with the Declaration of Helsinki and was approved by the Ethics Committee of Wujin People' Hospital.

\section{Baseline parameter analysis}

Baseline characteristics regarding gender, age, smoking, drinking, and diabetes mellitus (DM) were collected critically by investigators for all the patients from electronic medical records. Venous blood samples were collected from study cases in a fasting state on the morning following the admission day. The ABO blood groups of all the patients were determined. Plasma lipid levels including total cholesterol (TC), triglyceride (TG), low-density lipoprotein cholesterol (LDL-C), high-density lipoprotein cholesterol (HDL-C), apolipoprotein A-1 (ApoA-1) and apolipoprotein B (Apo B) were obtained using standard techniques. The atherogenic index of plasma (AIP) was calculated as Log (TG/HDL-C). The number of diseased coronary vessels with $\geq 50 \%$ stenosis was calculated in patients according to the selective coronary angiography.

\section{Gensini score assessment}

Severity of coronary artery stenosis was also evaluated by Gensini score (GS) based on the results of CAG for included cases [18]. Reduction in coronary lumen diameter of $25 \%, 50 \%, 75 \%, 90 \%, 99 \%$, and complete occlusion were counted as 1, 2, 4, 8, 16, and 32, respectively. A multiplier was then assigned to each main vascular segment based on the functional significance: 5 for the left main coronary artery, 2.5 for the proximal segment of the left anterior descending (LAD) coronary artery, 2.5 for the proximal segment of the left circumflex artery (LCX) , 1.5 for the mid-segment of the LAD, 1.0 for the distal segment of the LAD, mid-distal region of the LCX, the obtuse marginal artery, the right coronary artery and the posterolateral artery, 0.5 for other segments. The final score was calculated by adding the scores of each segment.

\section{Statistics analysis}

Continuous data with normal distribution was presented as mean \pm standard deviation (SD). The significance was evaluated by using the student $t$ test or ANOVA test. The remaining continuous data were represented as median [quartile ranges (QR)] and compared by using Mann-Whitney $U$ test among groups. Categorical data was reported as frequencies and percentages. Chi-square test was used to evaluate the significance. Multivariate logistic regression analysis was constructed to detect the effect of $A B O$ blood group on CAD. The regression model was established using forward Wald method. The inclusion level was set as 0.5 and the exclusion level was 0.1 . Odds ratio (OR) and $95 \%$ confidence

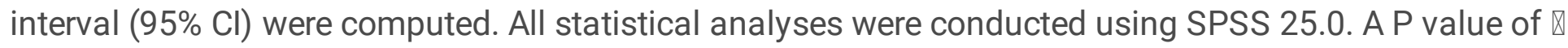
0.05 was considered to be statistically significant.

\section{Results}




\section{The baseline characteristics of study participants}

As shown in Table 1, the involved elderly and hypertensive patients were assigned into CAD group ( $\mathrm{n}=556$, aged $69.67 \pm 5.89$ years, $62.6 \%$ male) and non-CAD group ( $n=237$, aged $67.88 \pm 5.42 y e a r s, 44.3 \%$ male). Male gender was more prevalent among the CAD group. There were more smokers in the CAD group compare to the non-CAD group ( $\mathrm{p} \otimes 0.001)$. CAD patients were older, had a higher prevalence of DM, and also had significantly higher values of LDL-C, Apo B and AIP as compare to those with non-CAD (all $p \otimes 0.05)$. Compared with non-CAD group, CAD group had significantly lower levels of HDL-C and Apo A-1 ( $p$ all $₫ 0.01$ ). There were not different in TC and TG levels between the two groups.

The overall distribution of $A B O$ blood groups was different between those with and without CAD (A 36.0\% vs. $29.5 \%, A B 12.1 \%$ vs. $8.0 \%$, B $24.6 \%$ vs. $33.8 \%, 027.3 \%$ vs. $28.7 \%, p=0.022)$. Statistically lower frequency of $B$ was observed in CAD group than that in non-CAD group ( $33.8 \%$ vs. $24.6 \%, p=0.008)$.

\section{Table 1. Baseline characteristics of study participants with and without CAD}




\begin{tabular}{|c|c|c|c|}
\hline Variables & $\begin{array}{l}\text { Hypertensive elderly with CAD } \\
(n=556)\end{array}$ & $\begin{array}{l}\text { Hypertensive elderly without CAD } \\
(\mathrm{n}=237)\end{array}$ & $\begin{array}{l}P \\
\text { value }\end{array}$ \\
\hline Male, n (\%) & $348(62.6)$ & $105(44.3)$ & $\begin{array}{l}\square \\
0.001\end{array}$ \\
\hline $\begin{array}{l}\text { Smoking, n } \\
(\%)\end{array}$ & 196 (35.3) & 44(18.6) & $\begin{array}{l}\square \\
0.001\end{array}$ \\
\hline $\begin{array}{l}\text { Drinking, } \mathrm{n} \\
(\%)\end{array}$ & $67(12.1)$ & $22(9.3)$ & 0.258 \\
\hline Age, y & $69.67 \pm 5.89$ & $67.88 \pm 5.42$ & $\begin{array}{l}\square \\
0.001\end{array}$ \\
\hline DM, n (\%) & 185 (33.3) & $53(22.4)$ & 0.002 \\
\hline $\mathrm{TC}, \mathrm{mmol} / \mathrm{L}$ & $4.61 \pm 1.05$ & $4.46 \pm 0.99$ & 0.053 \\
\hline $\mathrm{TG}, \mathrm{mmol} / \mathrm{L}$ & $1.49(1.08-2.04)$ & 1.40(1.03-2.06ه & 0.280 \\
\hline $\begin{array}{l}\mathrm{HDL}-\mathrm{C} \\
\mathrm{mmol} / \mathrm{L}\end{array}$ & $1.10 \pm 0.26$ & $1.17 \pm 0.31$ & 0.001 \\
\hline $\begin{array}{l}\mathrm{LDL}-\mathrm{C}, \\
\mathrm{mmol} / \mathrm{L}\end{array}$ & $2.91 \pm 0.90$ & $2.61 \pm 0.78$ & 0.001 \\
\hline Apo A-1, g/L & $1.21 \pm 0.23$ & $1.27 \pm 0.24$ & 0.001 \\
\hline Apo $B, g / L$ & $0.95 \pm 0.26$ & $0.89 \pm 0.24$ & 0.005 \\
\hline AIP & $0.15 \pm 0.28$ & $0.11 \pm 0.29$ & 0.047 \\
\hline ABO, n (\%) & & & 0.022 \\
\hline A & $200(36.0)$ & 70 (29.5) & 0.080 \\
\hline$A B$ & $67(12.1)$ & $19(8.0)$ & 0.094 \\
\hline B & $137(24.6)$ & $80(33.8)$ & 0.008 \\
\hline 0 & $152(27.3)$ & $68(28.7)$ & 0.697 \\
\hline
\end{tabular}

\section{Lipid profiles between B and non-B blood groups in elderly with hypertension}

Comparison of lipid profiles between B and non-B blood groups were presented in Table 2. Data revealed that hypertension elderly with $B$ blood group had significantly lower concentrations of TC, LDL-C, and Apo $B$ than those with non-B blood groups ( $p=0.008,0.010$ and 0.007 , respectively). Moreover, there were not statistically higher levels of HDL-C, Apo A1 and AIP in B blood group as compared to non-B blood groups $(p=0.778,0.123$ and 0.377 , respectively).

\section{Table 2. Lipid profiles between B and non-B blood groups}




\begin{tabular}{llll} 
Lipids & B blood group $(\mathbf{n}=\mathbf{2 1 7})$ & Non-B blood group $(\mathbf{n}=576)$ & P value \\
\hline TC, mmol/L & $4.41 \pm 0.97$ & $4.63 \pm 1.06$ & 0.008 \\
\hline TG, mmol/L & $1.4(1.01-2.04)$ & $1.49(1.09-2.07)$ & 0.237 \\
\hline HDL-C, mmol/L & $1.11 \pm 0.28$ & $1.12 \pm 0.28$ & 0.778 \\
\hline LDL-C, mmol/L & $2.70 \pm 0.73$ & $2.86 \pm 0.92$ & 0.010 \\
\hline Apo A-1, g/L & $1.21 \pm 0.25$ & $1.24 \pm 0.23$ & 0.123 \\
\hline Apo B, g/L & $0.89 \pm 0.25$ & $0.94 \pm 0.26$ & 0.007 \\
\hline AIP & $0.13 \pm 0.28$ & $0.15 \pm 0.28$ & 0.377
\end{tabular}

\section{Severity of coronary artery stenosis and B blood group in hypertensive elderly}

Table 3 showed that hypertensive elderly patients with B blood group were more likely to have significantly lower number of diseased coronary vessels than those with non-B blood groups $(p=0.031)$. In addition, After Gensini score was assigned into 1st tertile (0-11.5), 2ed tertile (11.5-35.5) and 3rd tertile (>35.5), data revealed that B blood group tended to be associated with significantly lower Gensini score tertile when compared to non-B blood groups. But statistical difference was not obtained $(p=0.215)$.

\section{Table 3. Coronary stenosis severity between B and non-B blood group}

\begin{tabular}{|llll|}
\hline Variable & B blood group ( $\mathbf{n = 2 1 7 )}$ & Non-B blood group $(\mathbf{n = 5 7 6 )}$ & P value \\
\hline Number of diseased vessels & & & 0.031 \\
\hline 0 & $80(36.9)$ & $158(27.4)$ & \\
\hline 1 & $64(29.5)$ & $184(31.9)$ & \\
\hline$\geq 2$ & $73(33.6)$ & $234(40.6)$ & 0.215 \\
\hline Gensini score & & & \\
\hline 1st tertile (0-11.5), $\mathrm{n}(\%)$ & $82(37.8)$ & $181(31.4)$ & \\
\hline 2ed tertile (11.5-35.5), $\mathrm{n}(\%)$ & $65(30.0)$ & $199(34.5)$ & \\
\hline 3rd tertile (>35.5), $\mathrm{n}(\%)$ & $70(32.3)$ & $196(34.0)$ & \\
\hline
\end{tabular}

\section{Logistic regression analysis of B blood group and CAD in elderly with hypertension}

Binary multivariate logistic regression was conducted to establish whether B blood group was an independent factor for CAD risk in the patients. According to the univariate regression results shown in Table 4, variables including age (OR 1.057, 95\% Cl 1.028-1.087) , male gender (OR 2.103, 95\% Cl 1.5452.863) , smoking (OR 2.388, 95\% Cl 1.648-3.460) , DM (OR 1.731, 95\% Cl 1.217-2.464), and HDL-C (OR $0.375,95 \%$ Cl 0.219-0.642) , LDL-C (OR 1.524, 95\% Cl 1.262-1.840) , Apo A1 (OR 0.338, 95\% Cl 0.177- 
0.645) , Apo B (OR 2.420, 95\% Cl 1.299-4.510) and B blood group (OR 0.642, 95\% Cl 0.461-0.894) were included in the model.

After adjustment for such cardiovascular risk factors, multiple logistic regression analysis indicated that B blood group remained an independent protective factor of CAD (OR 0.642, 95\% $\mathrm{Cl} 0.450-0.916)$ in elderly patients. Moreover, age, male gender, smoking, DM, LDL-C and AIP were significantly related with increased risk of $\mathrm{CAD}(\mathrm{OR}=1.068,95 \% \mathrm{Cl} 1.037-1.100 ; \mathrm{OR}=1.972,95 \% \mathrm{Cl} 1.329-2.928 ; \mathrm{OR}=1.966,95 \% \mathrm{Cl}$ 1.244-3.108; $\mathrm{OR}=2.085,95 \% \mathrm{Cl} 1.420-3.060, \mathrm{OR}=1.706,95 \% \mathrm{Cl} 1.388-12.096$, and $\mathrm{OR}=1.737, \mathrm{Cl}$ $1.006 \sim 2.998$, respectively). HDL-C was an independently protective factor for CAD (OR $=0.422,95 \% \mathrm{Cl}$ 0.236-0.753, Table 5).

Table 4. Univariate regression analysis for risk factors and CAD

\begin{tabular}{lllllll} 
Variable & B & S.E & Wald & Sig. & Exp (B) & $95 \% \mathrm{Cl}$ \\
\hline Male & 0.744 & 0.157 & 22.308 & 0.000 & 2.103 & $1.545 \sim 2.863$ \\
\hline Age & 0.055 & 0.014 & 15.413 & 0.000 & 1.057 & $1.028 \sim 1.087$ \\
\hline Smoking & 0.871 & 0.189 & 21.174 & 0.000 & 2.388 & $1.648 \sim 3.460$ \\
\hline Drinking & 0.292 & 0.259 & 1.271 & 0.260 & 1.339 & $0.806 \sim 2.225$ \\
\hline DM & 0.549 & 0.180 & 9.295 & 0.002 & 1.731 & $1.217 \sim 2.464$ \\
\hline TC & 0.147 & 0.076 & 3.726 & 0.054 & 1.159 & $0.998 \sim 1.346$ \\
\hline TG & 0.061 & 0.071 & 0.737 & 0.391 & 1.063 & $0.924 \sim 1.223$ \\
\hline HDL-C & -0.981 & 0.275 & 12.734 & 0.000 & 0.375 & $0.219 \sim 0.642$ \\
\hline LDL-C & 0.421 & 0.096 & 19.108 & 0.000 & 1.524 & $1.262 \sim 1.840$ \\
\hline Apo A1 & -1.086 & 0.330 & 10.812 & 0.001 & 0.338 & $0.177 \sim 0.645$ \\
\hline Apo B & 0.884 & 0.318 & 7.750 & 0.005 & 2.420 & $1.299 \sim 4.510$ \\
\hline AIP & 0.552 & 0.279 & 3.927 & 0.048 & 1.737 & $1.006 \sim 2.998$ \\
\hline B blood group & -0.444 & 0.169 & 6.893 & 0.009 & 0.642 & $0.461 \sim 0.894$
\end{tabular}

Table 5. Multiple logistic regression analysis for risk factors with CAD 


\begin{tabular}{lllllll} 
Variable & B & S.E & Wald & Sig. & Exp (B) & 95\% Cl \\
\hline Age & 0.065 & 0.015 & 18.893 & 0.000 & 1.068 & $1.037 \sim 1.100$ \\
\hline Male & 0.679 & 0.202 & 11.352 & 0.001 & 1.972 & $1.329 \sim 2.928$ \\
\hline Smoking & 0.676 & 0.234 & 8.379 & 0.004 & 1.966 & $1.244 \sim 3.108$ \\
\hline DM & 0.735 & 0.196 & 14.068 & 0.000 & 2.085 & $1.420 \sim 3.060$ \\
\hline HDL-C & -.864 & 0.296 & 8.521 & 0.004 & 0.422 & $0.236 \sim 0.753$ \\
\hline LDL-C & 0.534 & 0.105 & 25.828 & 0.000 & 1.706 & $1.388 \sim 2.096$ \\
\hline B blood group & -.443 & 0.181 & 5.973 & 0.015 & 0.642 & $0.450 \sim 0.916$
\end{tabular}

\section{Discussion}

In this cross-sectional study, we sought to explore the association of $A B O$ blood groups with the incidence of $C A D$, as well as the CAD severity in elderly individuals with hypertension. We obtained two essential results of the association between $B$ blood group and newly angiography-diagnosed CAD in hypertensive elderly. Firstly, after adjusting for the confounding factors, the association of B blood group with a decreased risk of CAD was initially observed in elderly with hypertension. Secondly, statistically lower number of significantly diseased coronary vessels was detected in hypertensive elderly with B blood group when compared to those with non-B blood groups.

It is known that $A B O$ blood group antigens have been demonstrated to express not only on the surface of red blood cell but also on a variety of human tissues such as epithelium, platelets and vascular endothelium [19]. Thus, ABO blood group is considered as a risk factor for cardiovascular and thrombotic diseases $[20,21,22,23]$. It has been shown in previous studies that individuals with blood group $A$ have a higher risk of CAD compared with non-A blood groups. Furthermore, second CAG indicates that in-stent restenosis is significantly more prevalent in individuals with blood group A compared to other blood groups [24]. In the meanwhile, several studies reveal that ABO blood groups are not associated with CAD in general population $[25,26]$. However, Whether $B$ blood group is associated with CAD remains controversial in Chinese prior papers. And few reports pay attention to the association of $B$ blood group with CAD risk and severity, especially in elderly and hypertensive subjects who suffer from cardiovascular disease burden.

In the present study, we investigated the association between ABO blood types and CAD defined by primary CAG in the Chinese elderly population with hypertension. Our results revealed that no significantly higher frequency of blood group A was observed in elderly and hypertensive patients with CAD than the rest of the population. It was also different from the results of previous study which indicates that blood group $A$ is an independent risk factor for CAD and $\mathrm{Ml}$ in Chinese young population [17]. To our knowledge, the available evidence suggest that $O$ blood group is related with a decreased risk of CAD in general subjects. Furthermore, research conducted in India showed that AB blood group decreased the risk of 
CAD due to the higher concentration of HDL-C in general population [10]. However, the relationships were not observed among the elderly adults in our study. Apart from this, our data revealed that hypertensive elderly with $B$ blood group had a significantly lower risk of CAD than those with non-B blood groups. Further analysis suggested that B blood group was an independently protective factor for incident CAD. The results contrasted observations of $B$ blood group as a predictor of CAD among general subjects [27]. The possible mechanism underling these variations due to the enrollment of patients from different race or population. Furthermore, a recent study suggested that although there were no differences between blood group $\mathrm{O}$ or $\mathrm{B}$ compared with $\mathrm{A}$ or $\mathrm{AB}$ for serum inflammatory cytokines, patients with blood group $\mathrm{O}$ or $B$ had reduced risk for disease severity and multiorgan dysfunction in COVID-19 [28]. Moreover, it is reported that patients with $\mathrm{O}$ have decreased levels of factor VII and von Willebrand factor, which may account for the underlying protective effect against cardiovascular disease $[21,29]$. Central to the findings, further studies are required to delineate the biological mechanisms of our results, which have not been elucidated for lack of essential data.

It has been long recognized that TG and LDL-C are common risk factors, and HDL-C, Apo A1 are protective factors for cardiovascular disease or major adverse cardiac events after percutaneous coronary intervention $[30,31,32]$. The AIP is strongly associated with atherogenesis of the coronary artery. In the present study, we similarly found that patients with CAD were more likely to have higher levels of LDL-C Apo B and AIP, and lower concentration of HDL-C and Apo A-1. Schmitz $G$ et al found that the prototypic ATP binding cassette transporter $A B C A 2$ which plays a pivotal role in transmembrane cholesterol export, as well as the ABO gene locate on chromosome $9 q 34$ [33]. Based on these, studies have been conducted to explore the potential relation of $A B O$ blood group to lipid metabolism in incidence and development of CAD. Higher plasma levels of TC and LDL-C have been shown to be involved in the association between ABO blood group and incident CAD. Around 10\% of the effect of non$O$ type on CAD and myocardial infarction susceptibility was mediated by its influence on LDL-C level $[34,35,36]$. Consistent with the previous finding, our data revealed that hypertensive elderly with B blood group had significantly lower concentrations of LDL-C, and Apo B than those with non-B blood groups. Likewise, the results of our study demonstrated that TC, LDL-C and Apo B might play an important role in the effect of $B$ blood group on the decreased risk of CAD. Consistent with previous studies, LDL-C was associated with increased risk of CAD, and HDL-C was a protective factor for CAD.

A blood group as a risk factor for CAD has been shown to be positively associated with the severity of coronary atherosclerosis assessed by Gensini score.7 Inconsistent with the study, a report conducted in Chinese young people showed no consistent association of ABO blood groups with CAD severity estimated using significantly diseased vessels [17].Whereas, the findings of our study reflected that hypertensive elderly with B blood group were more likely to have significantly lower number of diseased vessels. Although statistical difference was not observed, hypertension elderly with B blood group was prone to have low level of Gensini score, which provided additional evidence for the association. These might lead to the benefits for seniors with hypertension and B blood group. It was helpful for identifying high-risk elderly individuals early and reducing the risk of cardiovascular events. 
There were several limitations in the present study. First, this study was a retrospective study, in which several risk factors including BMI and uric acid were absent. Second, it was a single-center study conducted in a selected group of Chinese patients. The results might be biased for relatively small sample. Third, there was insufficient mechanism to explain the association of B blood group with CAD in the population. Therefore, larger samples, multicenter and prospective studies are needed to confirm our findings in elderly patients with hypertension.

\section{Conclusion}

Collectively, the current study revealed that B blood group represented a protective factor of CAD in Chinese hypertensive population aged 60 years or older.

\section{Abbreviations}

CAD: coronary artery disease

CAG: coronary angiography

HBP: high blood pressure

DM: diabetes mellitus

TC: total cholesterol

TG: triglyceride

LDL-C: low-density lipoprotein cholesterol

HDL-C: high-density lipoprotein cholesterol

Apo A-1: apolipoprotein A-1

Apo B: apolipoprotein B

AIP: atherogenic index of plasma

\section{Declarations}

\section{Ethics approval and consent to participate}

The study was approved by the ethics committee of Wujin Hospital Affiliated with Jiangsu University, Changzhou, China. The written informed consents were not presented from the included patients because the relevant data were retrospectively obtained from the electronic medical records. 
Not applicable.

\section{Availability of data and materials}

All data relevant to the study are included in the article used for analysis during the current study are available from the corresponding author on reasonable request.

\section{Competing interests}

The authors declare that they have no competing interests.

\section{Funding}

Not applicable.

\section{Authors' contributions}

Yanbin Song was responsible for initial manuscript writing. Yanbin and Gaojun Cai reviewed the paper and were responsible for the final version of the manuscript. All authors read and approved the final manuscript.

\section{Acknowledgements}

We are grateful to the colleagues at the Department of cardiology, Wujin Hospital Affiliated with Jiangsu University, Changzhou, China.

\section{References}

1. Bibbins-Domingo K; U.S. Preventive Services Task Force. Aspirin Use for the Primary Prevention of Cardiovascular Disease and Colorectal Cancer: U.S. Preventive Services Task Force Recommendation Statement. Ann Intern Med. 2016;164(12):836-45.

2. GBD 2017 Causes of Death Collaborators. Global, regional, and national age-sex-specific mortality for 282 causes of death in 195 countries and territories, 1980-2017: a systematic analysis for the Global Burden of Disease Study 2017. Lancet. 2018;392(10159):1736-88.

3. Nichols M, Townsend N, Scarborough P, Rayner M. Cardiovascular disease in Europe 2014: epi demiological update. Eur Heart J. 2014;35(42):2929.

4. Rosamond W, Flegal K, Furie K, Go A, Greenlund K, Haase N, et al; American Heart Association Statistics Committee and Stroke Statistics Subcommittee. Heart disease and stroke statistics-2008 update: a report from the American Heart Association Statistics Committee and Stroke Statistics Subcommittee. Circulation. 2008;117(4):e25-146.

5. Rydén L, Grant PJ, Anker SD, Berne C, Cosentino F, Danchin N, et al. ESC Guidelines on diabetes, prediabetes, and cardiovascular diseases developed in collaboration with the EASD: the Task Force on diabetes, pre-diabetes, and cardiovascular diseases of the European Society of Cardiology (ESC) and 
developed in collaboration with the European Association for the Study of Diabetes (EASD). Eur Heart J. 2013;34(39):3035-87.

6. Lee JS, Chang PY, Zhang Y, Kizer JR, Best LG, Howard BV. Triglyceride and HDL-C Dyslipidemia and Risks of Coronary Heart Disease and Ischemic Stroke by Glycemic Dysregulation Status: The Strong Heart Study. Diabetes Care. 2017;40(4):529-37.

7. Gong P, Luo SH, Li XL, Guo YL, Zhu CG, Xu RX, et al. Relation of ABO blood groups to the severity of coronary atherosclerosis: an Gensini score assessment. Atherosclerosis. 2014;237(2):748-53.

8. Carpeggiani C, Coceani M, Landi P, Michelassi C, L'abbate A. ABO blood group alleles: A risk factor for coronary artery disease. An angiographic study. Atherosclerosis. 2010;211(2):461-6.

9. Biswas J, Islam MA, Rudra S, Haque MA, Bhuiyan ZR, Husain M, et al. Relationship between blood groups and coronary artery disease. Mymensingh Med J. 2008;17(2 Suppl):S22-7.

10. Biswas S, Ghoshal PK, Halder B, Mandal N. Distribution of ABO blood group and major cardiovascular risk factors with coronary heart disease. Biomed Res Int. 2013;2013:782941.

11. Liu MQ, Ji SR, Xu WY, Liu WS, Qin Y, Xiang JF, et al. ABO Blood Group and the Risk of Pancreatic Neoplasms in Chinese Han Population: A Study at Shanghai Pancreatic Cancer Institute. Pancreas. 2019;48(9):e65-6.

12. Zindovic I, Edgren G, Nozohoor S, Majeed A. ABO blood group and the risk of aortic disease: a nationwide cohort study. BMJ Open. 2020;10(10):e036040.

13. Abrignani MG, Aiello A, Colivicchi F, Lucà F, Fattirolli F, Gulizia MM, et al. Prevenzione cardiovascolare negli anziani: limiti e opportunità [Cardiovascular prevention in the elderly: limitations and opportunities]. G Ital Cardiol (Rome). 2020;21(8):619-28.

14. Chan MY, Woo KS, Wong HB, Chia BL, Sutandar A, Tan HC. Antecedent risk factors and their control in young patients with a first myocardial infarction. Singapore Med J. 2006;47(1):27-30.

15. Zimmerman FH, Cameron A, Fisher LD, Ng G. Myocardial infarction in young adults: angiographic characterization, risk factors and prognosis (Coronary Artery Surgery Study Registry). J Am Coll Cardiol. 1995;26(3):654-61.

16. Incalcaterra E, Caruso M, Lo Presti R, Caimi G. Myocardial infarction in young adults: risk factors, clinical characteristics and prognosis according to our experience. Clin Ter. 2013;164(2):e77-82.

17. Lee HF, Lin YC, Lin CP, Wang CL, Chang CJ, Hsu LA. Association of blood group A with coronary artery disease in young adults in Taiwan. Intern Med. 2012;51(14):1815-20.

18. Gensini GG. A more meaningful scoring system for determining the severity of coronary heart disease. Am J Cardiol. 1983;51(3):606.

19. Dean L. Blood Groups and Red Cell Antigens. Bethesda (MD): National Center for Biotechnology Information (US); 2005. Available from: http://www.ncbi.nlm.nih.ov/books/NBK2267.

20. Franchini M, Mannucci PM. ABO blood group and thrombotic vascular disease. Thromb Haemost. 2014;112(6):1103-9. 
21. Franchini M, Capra F, Targher G, Montagnana M, Lippi G. Relationship between ABO blood group and von Willebrand factor levels: from biology to clinical implications. Thromb J. 2007;5:14.

22. Vasan SK, Rostgaard K, Majeed A, Henrik U, Titlestad KE, Pedersen OB, et al. ABO Blood Group and Risk of Thromboembolic and Arterial Disease: A Study of 1.5 Million Blood Donors. Circulation. 2016;133(15):1449-57.

23. Groot HE, Villegas Sierra LE, Said MA, Lipsic E, Karper JC, van der Harst P. Genetically Determined ABO Blood Group and its Associations With Health and Disease. Arterioscler Thromb Vasc Biol. 2020;40(3):830-8.

24. Pourafkari L, Ghaffari S, Ahmadi M, Tajlil A, Nader ND. Association of ABO blood types with the risk of in-stent restenosis. Perfusion. 2015;30(6):507-13.

25. Karabuva S, Carević V, Radić M, Fabijanić D. The association of ABO blood groups with extent of coronary atherosclerosis in Croatian patients suffering from chronic coronary artery disease. Biochem Med (Zagreb). 2013;23(3):351-9.

26. Sari I, Ozer O, Davutoglu V, Gorgulu S, Eren M, Aksoy M. ABO blood group distribution and major cardiovascular risk factors in patients with acute myocardial infarction. Blood Coagul Fibrinolysis. 2008;19(3):231-4.

27. Biancari F, Satta J, Pokela R, Juvonen T. ABO blood group distribution and severity of coronary artery disease among patients undergoing coronary artery bypass surgery in Northern Finland. Thromb Res. 2002;108(2-3):195-6.

28. Hoiland RL, Fergusson NA, Mitra AR, Griesdale DEG, Devine DV, Stukas S, et al. The association of $A B O$ blood group with indices of disease severity and multiorgan dysfunction in COVID-19. Blood Adv. 2020;4(20):4981-9.

29. Murray GP, Post SR, Post GR. ABO blood group is a determinant of von Willebrand factor protein levels in human pulmonary endothelial cells. J Clin Pathol. 2020;73(6):347-9.

30. Koncsos P, Fülöp P, Juhász I, Bíró K, Márk L, Simonyi G, et al. Changes in triglyceride, HDL-C, and nonHDL-C levels in patients with acute coronary syndrome. Wien Klin Wochenschr. 2016;128(23-24):85863.

31. Stein R, Ferrari F, Scolari F. Genetics, Dyslipidemia, and Cardiovascular Disease: New Insights. Curr Cardiol Rep. 2019;21(8):68.

32. Seo SM, Choo EH, Koh YS, Park MW, Shin DI, Choi YS, et al. High-density lipoprotein cholesterol as a predictor of clinical outcomes in patients achieving low-density lipoprotein cholesterol targets with statins after percutaneous coronary intervention. Heart. 2011;97(23):1943-50.

33. Schmitz G, Kaminski WE. ABCA2: a candidate regulator of neural transmembrane lipid transport. Cell Mol Life Sci. 2002;59(8):1285-95.

34. Chen Y, Chen C, Ke X, Xiong L, Shi Y, Li J, et al. Analysis of circulating cholesterol levels as a mediator of an association between $A B O$ blood group and coronary heart disease. Circ Cardiovasc Genet. 2014;7(1):43-8. 
35. Gong P, Li S, Hu L, Luo S, Li J, Jiang H. [Total cholesterol mediates the effect of ABO blood group on coronary heart disease]. Zhonghua Xin Xue Guan Bing Za Zhi. 2015;43(5):404-7.

36. Silbernagel G, Chapman MJ, Genser B, Kleber ME, Fauler G, Scharnagl H, et al. High intestinal cholesterol absorption is associated with cardiovascular disease and risk alleles in ABCG8 and ABO: evidence from the LURIC and YFS cohorts and from a meta-analysis. J Am Coll Cardiol. 2013;62(4):291-9. 